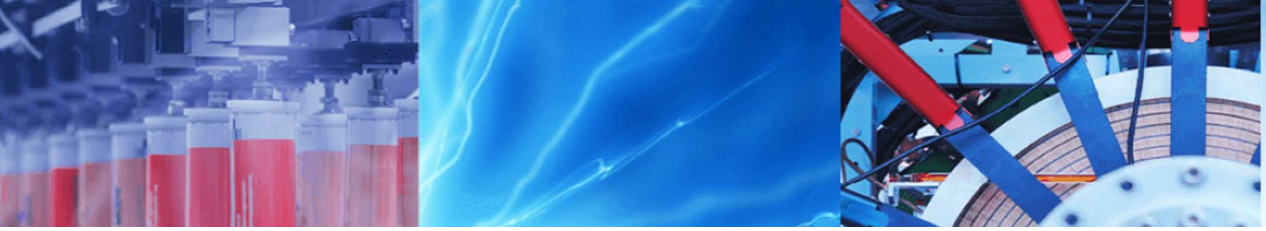

Research Article

\title{
Assessment of public open spaces (POS) and landscape quality based on per capita POS index in Delhi, India
}

\author{
Shahfahad ${ }^{1} \cdot$ Babita Kumari $^{1} \cdot$ Mohammad Tayyab $^{1,2} \cdot$ Hoang Thi Hang $^{1} \cdot$ Mohammad Firoz Khan $^{1} \cdot$ Atiqur Rahman $^{1}$
}

(c) Springer Nature Switzerland AG 2019

\begin{abstract}
Public open spaces and green cover are a connection between people and nature and are necessary to retain the quality of the urban landscape. Rapid urban growth and population increase put tremendous pressure on public open spaces, which reduces the quality of the urban landscape. The fast urban growth leads to utilize remaining green and open areas of the city for different purposes. As a result, the size of the urban green and open space is decreasing at an alarming rate. Therefore, the study analyses the availability of per capita public open spaces to assess the landscape quality. The green space available per capita in Delhi is about $20 \mathrm{~m}^{2}$, and public open space is $30 \mathrm{~m}^{2}$. Weights have been assigned to five variables selected to assess the landscape quality, and then, it was multiplied by the respective $z$ score (scalefree) of each variable. Finally, we have calculated composite index score to develop a landscape quality index. The per capita share of public open spaces in East Delhi is $7.01 \mathrm{~m}^{2}$ to its total area. Wards with high population density have a comparatively low proportion of public open spaces. It is seen that most of the wards did not match the criteria of WHO and UN for per capita availability of public open spaces. The landscape quality index shows that in more than two-thirds of the wards, the landscape quality is poor. The wards of the central and northern parts of the study area are densely populated and have a low concentration of public open spaces; therefore, they have the least index score on landscape quality. At the same time, the wards of southeastern and eastern parts, where the population density is the lowest, the score of the landscape quality index is high.
\end{abstract}

Keywords Public open space (POS) · Population density · Remote sensing and GIS · Urban landscape quality

\section{Introduction}

The landscape is a crucial and complex term which is used differently in scientific disciplines and is variably defined. The literature on landscape indicates that it is approached differently in environmental science, urban studies, geography and other disciplines [5]. Some advocate for a holistic approach to understand landscape which is theoretically attractive, but difficult to implement. Therefore, there is a multitude of topical approaches, emphasizing one or other element or combination of elements of structure and functions of landscapes as a scientific aspect. The Council of Europe [12] in European Landscape Convention defines the landscape as a part of the geographical expanse (land), which evolves through time by operation of natural forces and human actions. As such, it contains both natural and anthropogenic elements. Bruni [3] puts it as'landscape can be identified as a combination of natural

Electronic supplementary material The online version of this article (https://doi.org/10.1007/s42452-019-0372-0) contains supplementary material, which is available to authorized users.

$\triangle$ Atiqur Rahman, ateeqgeog@yahoo.co.in; Shahfahad, fahadshah921@gmail.com; Babita Kumari, pihu.mital@gmail.com; Mohammad Tayyab, tayyab617@gmail.com; Hoang Thi Hang, hlhangstac@gmail.com; Mohammad Firoz Khan, mohdfirozkh@gmail.com |'Department of Geography, Faculty of Natural Sciences, Jamia Millia Islamia, New Delhi 110025, India. ${ }^{2}$ Delhi Development Authority (DDA), New Delhi, India. 
and cultural assets.' Landscape, as a combination of all visible features of a geographical extent, is given to the senses of an intentional observer. By this reason, it (landscape) is a matter of perceived experience in environmental psychology and therefore subjective that can only be described and neither generalized nor quantified.

Whereas, the landscape quality is considered as a dynamic and complex mosaic of an interacting and interlinking network of various patches of habitats in which human live. To understand and define the landscape quality, one needs to understand the aspects of physical environment as well as public spaces [4]. Urban landscape quality encompasses a number of aspects including environmental pollution, cleanliness, visual and aesthetic quality and the public perception [17]. The landscape quality is an important aspect of sustainable urbanism, as its importance was recognized long before the emergence of the concept of sustainability [54]. As cities grow and expand, there is a need to maintain and manage green and open spaces in order to maintain the landscape quality. According to Council of Europe [13], landscape has an important public interest role in the cultural, ecological, environmental and social fields. Rogers [53] in his book 'Cities for a Small Planet' pointed that urban landscape quality is an important indicator of the sustainability of city. Reconstruction of Paris during second half of the nineteenth century is one of the examples where spaces were allotted within the city for parks and green spaces to improve the urban landscape quality [34]. Changing landscape pattern is an important part of the urban landscape sustainability $[18,66]$. The urban landscape broadly covers green areas, urban parks, gardens and small public gardens and lawns, which help to make a favourable and wholesome environment, collectively called public open spaces (POS). So these public open spaces play an important role in determining the landscape quality of any urban area.

The open spaces in Indian cities can be seen as public and private spaces which can be differentiated based on the ownership and accessibility. The public open spaces are the spaces which are open and accessible for the common people for the recreational and leisure facilities [57]. Public open spaces are the spaces that are freely accessible for the local residents, regardless of its size, design or structure which are intended primarily for basic recreational purposes [39] and are of great importance for the urban ecological balance. Public spaces like schoolyards, cemeteries, outdoor sports complexes and public squares all are important open spaces [24]. The open spaces, e.g. Eidgah (where the prayers of Eid are performed by the Muslims) and Ramleela maidan (where the play on life of Lord Ram is performed by the Hindus), which are owned by some religious or social groups are the semi-private spaces, whereas the private open spaces, e.g. kitchen gardens and courtyards, are usual outdoor areas which are exclusively used by the single dwelling units [37].

In an urban system, public open space is a basic type of land use along with residential complexes, commercial centres, industries, transport network, etc. In recent days, the rapid urban growth led to utilize remaining green and open areas of the city for different purposes. As a result of this, the size of the urban green and open space is decreasing at an alarming rate [27]. The decline in green and open spaces and rapid increase in urban population, ultimately results in declining per capita availability of public open spaces within the urban areas which leads to declining urban landscape quality $[9,56]$. World Health Organization (WHO) has set a minimum limit for the per capita green space in urban areas as $9 \mathrm{~m}^{2}$ for healthy living [35]. Minimum limit for the per capita green space has also been identified by the United Nations (UN) as $30 \mathrm{~m}^{2}$ per person and by European Union (EU) as $26 \mathrm{~m}^{2}$, but no specific limit for per capita public open spaces has been given by any agency [31, 38, 40,58]. The amount of green cover and size of open spaces, their spatial distribution and characteristics as well as other factors are important determinants of the quality of life of city residents and quality of urban environment [11] and are essential for the sustainability of an urban centre [25].

The public open spaces are necessity for good landscape quality as well as quality life, but due to ongoing rapid urbanization throughout the world, the distance between urban dwellers and nature is increasing, thereby decreasing urban landscape quality. With such significant benefits to quality of life, public open spaces in urban areas over the world are facing problems, e.g. encroachment and the deteriorating public open spaces in quantity (area) and quality (scarcity). Processes of densification and urban sprawl have wiped out green cover, water bodies and several public open spaces at the cost of residential and commercial development. In East and North-East Delhi too, high population density with the associated high built-up area is one of the major causes of the low quality of the urban landscape. Physical landscape and public open spaces offer many benefits to quality of life, e.g. physical and mental health [41], social interaction and economic value.

Along with other green surfaces, vegetation cover plays important role in balancing ecological setting of an urban landscape $[8,14]$. Green spaces are the vegetated areas seen within the urban boundary which includes parks, gardens, lawns, residential gardens, street trees, etc. They act as the lung of cities as they absorb carbon dioxide $\left(\mathrm{CO}_{2}\right)$ and release oxygen $\left(\mathrm{O}_{2}\right)$ thus purifies the urban air [26]. They also play important role in reducing the urban heat island (UHI) effect and land surface temperature (LST) within an urban area [65]. One of the major topics of 
urban environmental and territorial sustainability which concerns not only about environmental sustainability but also deals with social as well as cultural issues is landscape quality [5].

In order to assess the landscape quality, judicious selection of indicators is very important. The indicators of urban landscape quality are the sum total of all urban elements ranging from artificial to natural surfaces, the improvement in the landscape quality shall leads to improvement in quality of life of urban dwellers [4]. The environmental, cultural and morphological characteristics are the base of the indicators of landscape quality of a region which help to choose and put into practice by the local politics [3]. There are various methods of assessment of landscape quality which may depend on the types of indicators used [20]. Selecting the indicators for landscape sustainability and quality is a difficult task as it falls into the responsibility of various local authorities like urban planners, architects, decision makers, etc. [1]. A number of studies have applied landscape quality index in order to analyse the urban sustainability $[5,20,19,44]$ during the past few decades. In the age of remote sensing technology since 1972, the quantification of various indicators of public open spaces by using high-resolution satellite data is being done.

Sowińska-Świerkosz and Chmielewski [61] have assessed landscape quality based on public opinion. They used a method that links public and expert opinions in the process of the development of indicators of landscape quality. An indicator was developed to assess the ecological landscape quality (IELQ) based on the use of surrogate measures which includes landscape diversity, the degree of the ecological significance of land cover forms and the character of linear landscape structures for assessing ecological quality (EQ) and a GIS approach [59]. Indicators of natural landscape in terms of per capita availability, enables not only to rank the urban landscape but also reflects the human contact to natural landscape as well as human well-being [45]. Six indicators which may come under public or private were used to assess the urban landscape quality: 3 from type and characteristics of residential buildings, one each from urban infrastructure and green infrastructure and one as other landscape elements like water bodies, forests, etc. [20].

The main objective of the study is to analyse micro-level (ward-wise) quality of urban landscape in terms of public open spaces in the East and North-East Delhi, which is in one of the most densely populated parts of Delhi. After going through expert literature on landscape and guidelines provided $[1,2,20,43,50]$, we have selected five landscape elements as indicators of quality of landscape, considering their functions as landscape and contribution to the urban sustainability termed as POS. Four of them represent natural landscape features, i.e. open space, open green, parks and playground and vegetation cover. The last one is population density, as humans are the most dominant species and users of landscape. These five indicators are combined into a composite index for assessing the quality of the urban landscape. By nature, it is a topical study with emphasis on landscapes services at micro-level. It is novel in the sense that most scientific studies deal with configuration, structure and functions of the landscape including almost all conceivable aspects of the entire landscape or its different components.

\section{Study area}

Delhi is the second largest city in India with about 16.8 million populations [6]. It is the centre of the National Capital Region (NCR), which has only one of its kinds 'inter-state regional planning' area formed by the 'National Capital Region Planning Board Act of 1985'. The population density in Delhi is high due to immigration from other states mostly from Uttar Pradesh, Haryana and Bihar [51]. For the present study, we have selected eastern part of Delhi (commonly known as Yamuna Par), which consists of two districts: East and North-East districts (Fig. 1). These two districts together comprise of 64 municipal wards and have an area of $96.47 \mathrm{~km}^{2}$. The districts are divided from rest of Delhi by Yamuna River and are among the most densely populated districts of Delhi (40962 persons $/ \mathrm{km}^{2}$ ).

\section{Material and method}

\subsection{Material}

The data used in present study are secondary data as well as satellite data. The satellite images of East and North-East Delhi were captured from Google Earth which has a spatial resolution of $0.5 \mathrm{~m}$, to extract the various features from the images (Table 1). The Google Earth data which are freely available data (https://earth.google.com/web/) of month of March 2017 have been used for this study. The district and ward boundary based on 2017 Municipal Corporation of Delhi (MCD) election has been obtained from local MCD office, and the ward-wise population data have been obtained from the [6]; District Census Handbook, 2011. As the ward map is modified during each election, the name of some wards has been changed or some new wards have been created from older ones.

\subsection{Method}

We select eastern part of the Delhi as the study area to analyse the spatial distribution of POS and its relationship 


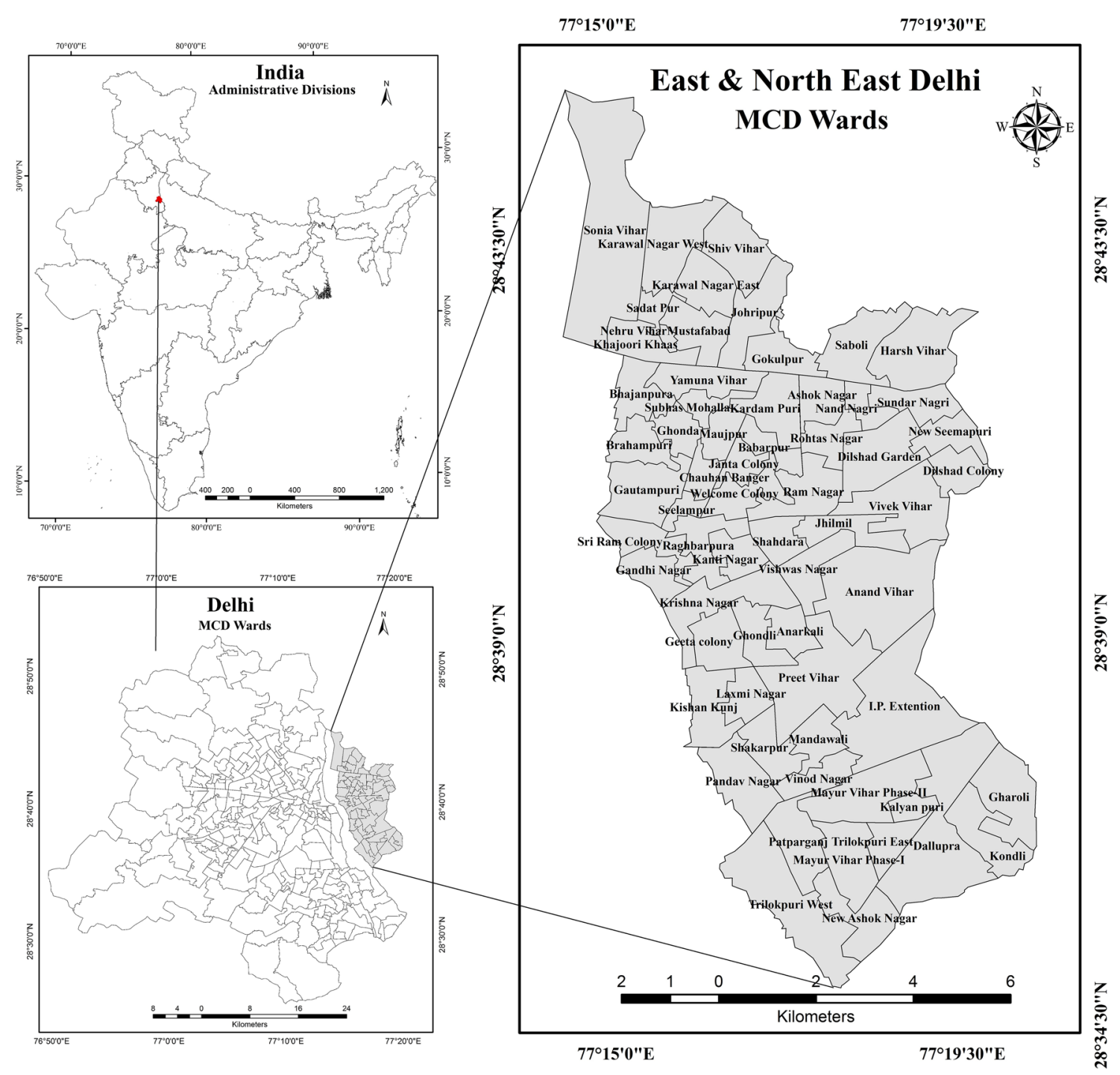

Fig. 1 Location of the study area

Table 1 Types of data used and their sources

\begin{tabular}{|c|c|c|c|c|}
\hline S. no. & Data source & Data type & Year & Extracted information \\
\hline 1 & Google Earth & $\begin{array}{l}\text { Satellite imageries } \\
\text { (0.5 m Spatial Resolu- } \\
\text { tion) }\end{array}$ & 2017 & $\begin{array}{l}\text { Parks, playgrounds, vegetation, } \\
\text { open area and open green } \\
\text { space }\end{array}$ \\
\hline 2 & Municipal Corporation & Ward map & 2017 & Ward boundary \\
\hline 3 & Census of India & Demographic data & 2011 & Ward-wise population \\
\hline
\end{tabular}

with the population distribution. Firstly, the satellite imageries were taken from Google Earth in tiles, and then, all the tiles were mosaic to get the full satellite scene of the study area. The indicators classified as POS for this study were then vectorized manually/visually in ArcMap 9.3, and finally, the matrix for the each indicator was calculated. Ward and district boundary obtained from local municipal corporation was also vectorized so that the extracted features can be superimposed over one another to draw the relationships. A general flowchart of methodology is given in Fig. 2.

The study of landscape characteristics is an important aspect of urban environmental studies. In this study, we have developed an index for landscape quality based on 
Fig. 2 Flowchart of the methodology

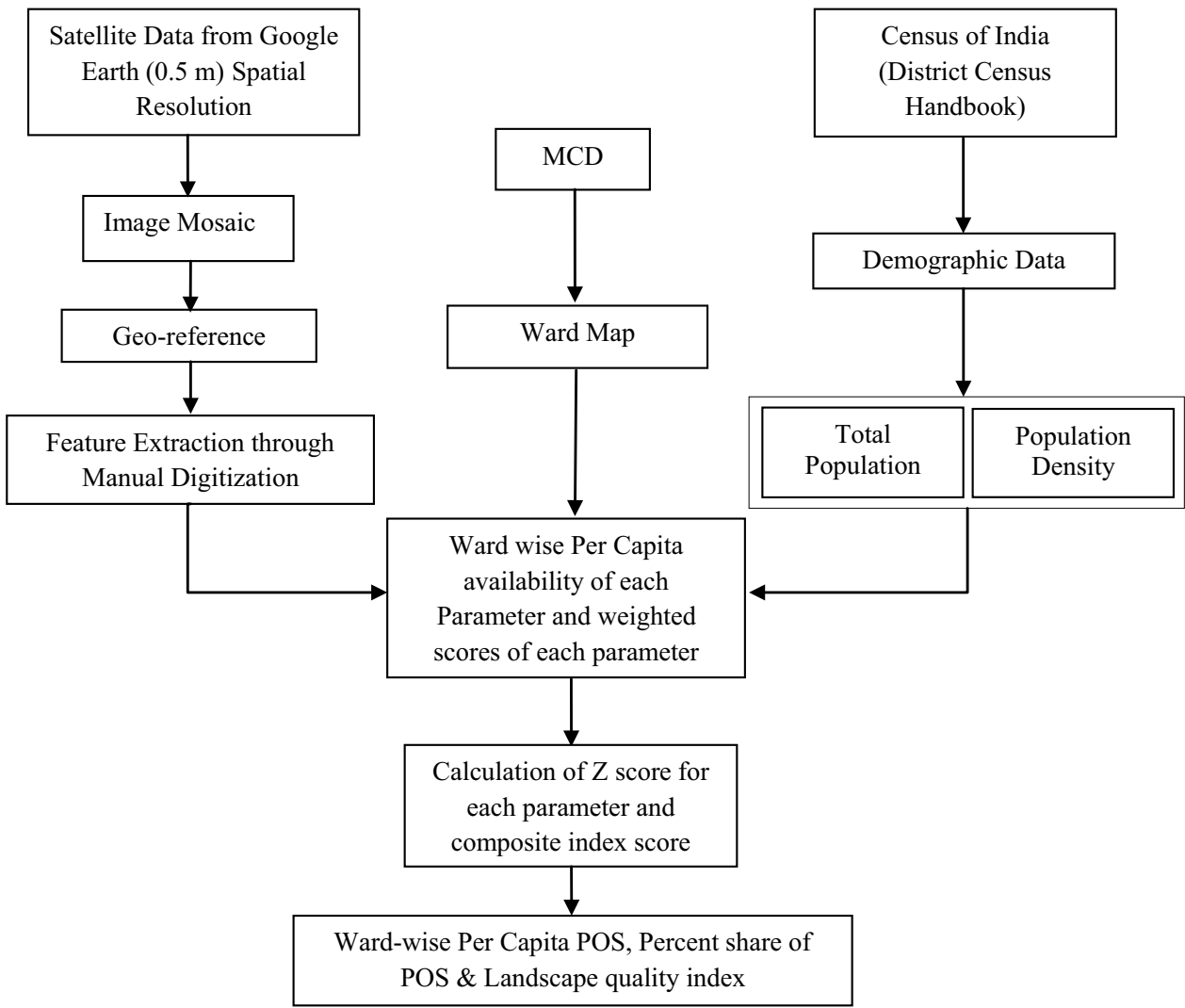

$Z$ score and weighted method. We assigned each indicator a weight based on their importance and then rearranged the weight as its sum becomes 1 . Then, we multiplied this weight of each indicator with the respective $Z$ score of that indicator of the urban landscape quality.

\subsubsection{Extraction of public open space (POS)}

The study uses four POS: (1) open land (without green), (2) open green patches (having short grasses), (3) parks and playgrounds and (4) vegetation cover (plantation and tree cover) as well as population density (Table 2) as the indicators to assess the landscape quality. Various types of open spaces like barren land, shrub land, urban forest, plantation, community parks, private gardens, religious grounds, etc., have been taken to assess the quality of landscape in Indian cities [29,37]. The typologies of public open spaces, e.g. open green, playground, open space, parks, plantation, urban forests, etc., have been used as indicators of urban landscape quality along with other indicators from human, cultural and environmental parameters to develop the urban landscape quality index $[4,3,7,16,20,64]$; therefore, we have selected the indicators based on these studies. The land which is vacant with or without short boundary walls and waste land without any green cover has been classified as open
Table 2 Classification of public open spaces

\begin{tabular}{lll}
\hline S. no. & Indicators & Description \\
\hline 1 & Vegetation & Vegetation along canals, roads, streets, etc. \\
& Urban forests and plantation \\
2 & Parks and playgrounds & Sports and leisure facilities \\
& & Parks and public sitting areas, etc. \\
3 & Open green patches & Residential gardens \\
& & Natural grass and shrub lands \\
4 & Open space/barren land & Barren lands and waste lands \\
& & School/courtyards \\
5 & Population density & -
\end{tabular}


space. The areas with short grasses and shrubs of any size and dimensions have been classified as open green. The public sitting spaces and gardens are classified as parks and playgrounds. The forested and plantation areas, trees along canals, streets and patches of green cover are classified as vegetation. The parks and playgrounds are the anthropogenic public space that reflects whether the area is planned or not. They offer physical activities like walking and leisure activities, while within residential areas they offer public sitting space.

These features selected as indicators of urban landscape quality in this study were extracted manually using very high-resolution satellite data in ArcMap 9.3 GIS software. The dense forest and tress along the roads and canals were easy to identify and were categorized into vegetation cover, while the open grasslands and sparse vegetation covers were categorized into open green. The parks and playgrounds are planned natural spaces which are easy to be identified on high-resolution satellite imageries, while open spaces are lands without any natural cover or man-made structure, which were also identified and extracted for the study.

\subsubsection{Calculation of per capita POS}

The demographic data obtained were used to find out the ward-wise population distribution and density. Choropleth method is used to plot population density using Arc Map 9.3, and the extracted features of urban landscape quality were thus overlaid to assess the relationships between population density and per capita POS. The ward-wise per capita availability (percentages) of POS has been calculated by using formula (1).

Per Capita POS (sq.m) $=\frac{\text { Total POS in a Ward }}{\text { Total Population of a Ward }}$

\subsubsection{Calculation of landscape quality index}

To calculate the landscape quality index firstly, the per capita availability of each indicator of urban landscape quality taken in this study, i.e. open space, open green, vegetation, etc., was calculated separately. Then, the $Z$ score of each indicator was calculated by using formula (2)

$Z_{i j}=\frac{x_{i j}-\mu_{i j}}{\sigma_{j}}$

where $i, j$ are the unit of observation and number of indicators, $x$ - per capita score of one indicator of a ward, $\mu$ mean score of that indicator of all wards, and $\sigma$-standard deviation of that indicator of all wards

\subsubsection{Weighting procedure}

Weights of indicators of quality of landscape in terms of LS and their utility are worked out using a twofold method. At first, thirty experts, including architects, environmental scientists, geographers, psychologists, sociologists and town and country planners, five each and 130 residents (users of LS), have been approached. They have been requested for their opinion and ranking of selected indicators. As regard opinions on the indicators, an overwhelming majority expressed priority for the presence of greenery in the city. However, in ranking priorities, some have the opinion that vegetation and parks and playground covered with grass are equally important. Nevertheless, as requested they ranked each indicator assigning a single value from one to five without repeating. Their ranking of indicators has been based on their expertise and experience.

The next step involved calculating relative weights of indicators of LS, using an online analytic hierarchy process (AHP) Priority Calculator (https://bpmsg.com/acade mic/ahp_calc.php). Since the method requires the input of positive integers to work out weights of variables. Out of ten choices, the rank of the variables decreases from highest to the lowest. The AHP algorithm used provides four ranking choices for the indicator with a rank of five. It gives three ranking choices for indicator ranking four, two choices for the next and only one for indicator with a rank of two. Therefore, in the case indicators of order five, four and three, it has been possible for rank inputs to be roughly in the proportion of those who assigned varying ranks to different indicators. Weights, thus worked out, have been reduced to the sum of one (1.0). However, considering the views of a majority of users and experts on building congestion/high population density as having a decorating effect on liveability, its weight obtained by the AHP method is given a negative sign. As a consequence, the sum of weights became less than one (1.0). In order, to make up the deficit, the difference of the sum from one has been proportionately distributed among the first four weights. It increased the value of positive weights but all the five weights, including negative one, summed to 1.0. The densely populated areas are negative areas from the point of the wholesome environment. Average of the rank score as assigned by the users and experts and final weights calculated by analytic hierarchy process (AHP) are given in Table 3.

Based on [20], relative weight of 1-5 has been assigned five indicators selected, and green spaces have been considered as the most important indicator of urban landscape analysis and urban highest weight of (5) is given to it, followed by parks and gardens/ playground and open spaces [19]. Hence, the present study has followed the Garau and Pavan [19] criteria to 
Table 3 Weights of different indicators of public open spaces

\begin{tabular}{lllrrr}
\hline Indicators & $\begin{array}{l}\text { Experts and users' } \\
\text { average weights }\end{array}$ & $\begin{array}{l}\text { Experts and users' average } \\
\text { weights (reduced to one) }\end{array}$ & $\begin{array}{l}\text { Integer } \\
\text { weights }\end{array}$ & $\begin{array}{c}\text { Weights by AHP } \\
\begin{array}{c}\text { AHP weights } \\
\text { accounted for negative } \\
\text { weight }\end{array}\end{array}$ \\
\hline Vegetation (w1) & 4.62 & 0.31579 & 5 & 0.51760 & 0.59072 \\
Parks and playgrounds (w2) & 3.97 & 0.27136 & 4 & 0.23052 & 0.26309 \\
Open green patches (w3) & 2.95 & 0.20163 & 3 & 0.11292 & 0.12886 \\
Open spaces/Barren land (w4) & 1.88 & 0.12851 & 2 & 0.07296 & 0.08333 \\
Population density (w5) & 1.21 & 0.08271 & 1 & 0.06600 & -0.06600 \\
Total & 14.63 & 1.00000 & 15 & 1.00000 & 1.00000 \\
\hline
\end{tabular}

assign the qualitative weight for assessing urban landscape quality. Population urban has assigned the least weight as it has a negative impact on landscape quality. Vegetation has been assigned the highest weight of 5 , because it acts as lungs of the urban environment, and also acts as the most important agent in the landscape quality and balances thermal properties of the land surface. Parks and playgrounds are the planned and maintained human as well as natural areas, which provide leisure and recreational facilities for people; thus, they have been assigned the weight of 4 , followed open green weight of 3 , open space a weight of 2 , the weights were sum up, and it has been divided by the weight of each indicator to find out the weighted scores by using formula (3).

Weighted score $(w)=\frac{\text { Assigned weight of the indicator }}{\text { Total weight of all indicators }}$

The composite index score has been calculated using formula (4)

$\mathrm{Cl}=\frac{\sum_{i j}^{m} w_{j} x_{i j}}{m}$

where $\mathrm{Cl}$-composite index scores, $w_{j}$-weights of indicators, $x_{i j}-z$ score of each indicator, $m$-number of indicators (5), $j-1, \ldots, m, i-1, \ldots, n$ (64 units of observations).

The $z$ score of all the indicators of urban landscape quality is multiplied by their respective weighted scores as calculated using formula (4) to get the composite index score for landscape quality. However, the weight of population density is negative because population density contributes negatively to the quality of landscape. This composite score was then classified into five classes by using standard deviation method, i.e. very low $(<\mu-0.5 \sigma)$, low $(\mu-0.5 \sigma$ to $\mu$ ), medium ( $\mu$ to $\mu+0.5 \sigma)$, high $(\mu+0.5 \sigma$ to $\mu+\sigma)$ and very high $(>\mu+1 \sigma)$.

\section{Results}

\subsection{Analysis of per capita public open spaces (POS)}

The spatial analysis of the per capita POS in the area revealed that 50 out of 64 wards are lacking in fulfilling even the criteria of $9 \mathrm{~m}^{2}$ 'per capita green space' as recommended by the WHO and only 14 wards fulfil the criteria of the WHO, whereas only two out of 64 wards (Sonia Vihar and Trilokpuri West) fulfil the criteria of $30 \mathrm{~m}^{2}$ 'per capita green space' as recommended by UN. The wards of south and south-western part of the study area have the highest per capita POS. The population density is low in these wards, and the availability of POS is also in significant proportion like Sonia Vihar $\left(49.16 \mathrm{~m}^{2}\right.$ per person). The western part of the study area also has sufficient per capita POS availability like IP extension $\left(27.20 \mathrm{~m}^{2}\right)$, while the wards of central part of the region like Babarpur, Ghonda, Nehru Vihar, etc., do not have sufficient per capita POS (Supplementary material on Appendix-I). Population density is the main determinant factor of per capita POS as the wards with high population density show low availability of per capita POS, while wards with low population density show sufficient availability of per capita POS (Fig. 3).

\subsection{Open spaces and open green}

The spatial analysis of percentage share of open space shows that Trilokpuri West has the highest per capita open space $\left(27.63 \mathrm{~m}^{2}\right)$, while Ghonda has lowest $\left(0.03 \mathrm{~m}^{2}\right)$. The per capita open space is highest in wards of south-east like IP extension, Dallupra, wards of south-west like Trilokpuri west and wards of north-west like Sonia Vihar which have close proximity to the Yamuna River bed (Fig. 4). The wards near to Yamuna River bed have low population density and abundant of open areas thus have high per capita 


\section{Ward wise Population Density \& Per-Capita POS}

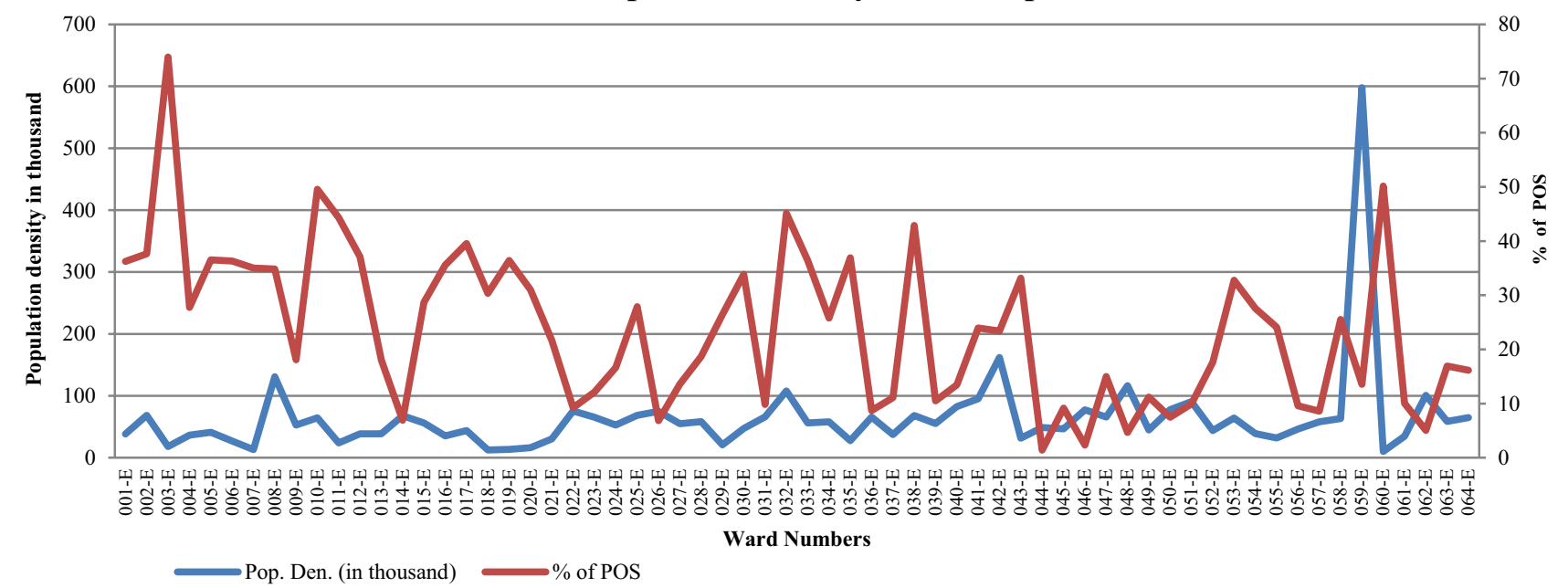

Fig. 3 Ward-wise population density and per capita POS

open space, while wards of central part of the region like Shahdara, Subhas Mohalla, Nehru Vihar, Laxmi Nagar, etc., have high population density and less open space thus have low per capita open space (Supplementary material on Appendix-I).

The per capita open green space is highest in wards of north-west like Sonia Vihar $\left(19.19 \mathrm{~m}^{2}\right)$ and south-west like Trilokpuri West $\left(12.59 \mathrm{~m}^{2}\right)$, while central wards like Ghonda $\left(0 \mathrm{~m}^{2}\right)$, Kanti Nagar $\left(0.1 \mathrm{~m}^{2}\right)$ and Babarpur $\left(0.1 \mathrm{~m}^{2}\right)$ have least per capita open green space. The wards of central part of the region like Seelampur, Shahdara, etc., and northern parts like Sadatpur have high population density and low open green space thus have low per capita green space, while some wards of southern part like Patparganj, western part like Pandav Nagar and eastern part like Anand Vihar and IP extension have comparatively high per capita open green space (Supplementary material on Appendix-1).

\subsection{Parks, playgrounds and vegetation}

Among different types of POS, playgrounds are observed in least proportion, followed by parks. Out of 64 wards, only 24 have at least one or more number of playgrounds, while parks are also absent from some wards of northern part of the region. The distribution of both parks and playgrounds is uneven in the region. The per capita parks and playgrounds are maximum in wards of south-east like Gharoli $\left(5.2 \mathrm{~m}^{2}\right)$ and Anand Vihar $\left(5.1 \mathrm{~m}^{2}\right)$, while central wards like Ghonda, Seelampur and Babarpur as well as northern wards like Karawal Nagar East, Shiv Vihar and Sadatpur are totally deficit in parks and playgrounds (Supplementary material on Appendix-I). Wards having high population density like Nehru Vihar, Shahdara, etc., have low per capita parks and playgrounds (Fig. 4).

Like parks and playgrounds, the distribution of vegetation is also sparse and uneven in the region. Opposite to the open and open green spaces, the vegetation cover is not available in sufficient proportion in the wards close to Yamuna River bed, while available in sufficient proportion in the wards of southern part of the region. The per capita vegetation cover is highest in Preet Vihar $\left(9.13 \mathrm{~m}^{2}\right)$, followed by IP extension $\left(5.24 \mathrm{~m}^{2}\right.$ ) and Dilshad Garden $\left(5.15 \mathrm{~m}^{2}\right)$. Most of the central wards except some like Preet Vihar, Vinod Nagar, etc., have low per capita green cover like Nehru Vihar, Laxmi Nagar, Kanti Nagar, etc. The eastern wards like Anand Vihar, Dallupra, etc., and south-western wards like Mayur Vihar Phase-I have high per capita vegetation cover (Supplementary material on Appendix-I), while the north-central wards like Kardam Puri, Ashok Nagar, etc., have low per capita green cover.

\subsection{Analysis of urban landscape quality}

The study shows that more than two-thirds of the wards of the study areas have very low and low index of landscape quality. Karl Pearson coefficient of correlation is applied which shows weak negative correlation $(-0.32)$ between population density public open spaces; it means higher the population density, lower the POS and lower the population density, higher the POS. The degree of correlation of population density with open space, open green, parks and playgrounds and vegetation is $-0.28,-0.23,-0.27$ and -0.29 , respectively; this again shows weak negative correlation. The study shows that composite index score of per capita POS ranges between -1.23 and 3.25 


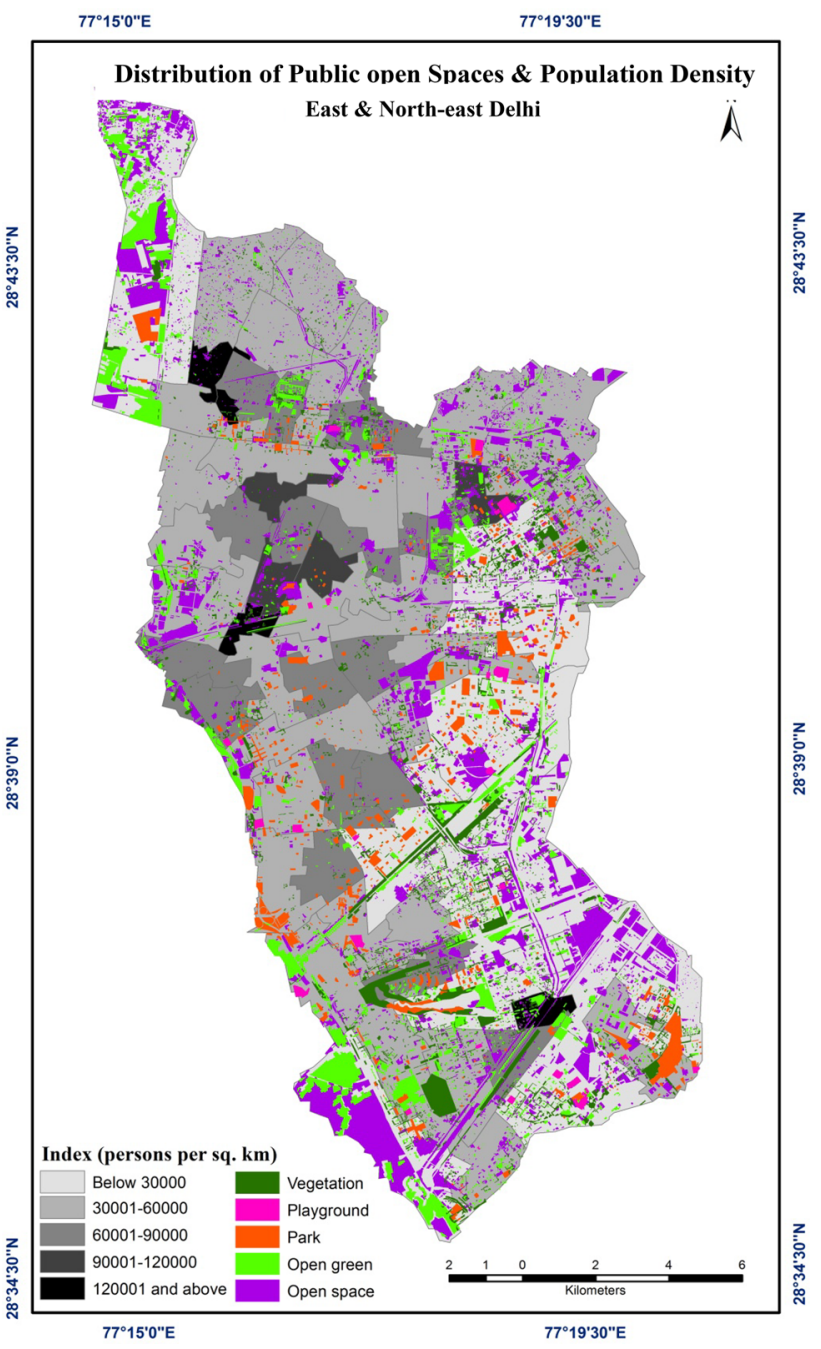

Fig. 4 Spatial distributions of POS and population density in East and North-East Delhi

(Supplementary material on Appendix-II). Out of sixty-four wards, twenty-six wards come under the very low category (below -0.43). It is why landscape quality in these wards is observed at its lowest. As many as fifteen wards come under the low category ( -0.42 to 0.01 ) of landscape quality, while nine wards come under medium category $(0.00-0.44)$ landscape quality. On the other hand, only three wards come under good category (0.45-0.88) and eleven wards come under the very good category $(0.89$ and above) of landscape quality.

The wards of south-eastern and eastern parts show the best landscape quality like Preet Vihar, Anand Vihar, IP extension, Dallupra, etc. The wards are located on Yamuna River bed like Sonia Vihar, and Trilokpuri West also shows the best quality of urban landscape. The abundance of open and open green spaces and low population density are the factors behind good quality of landscape in

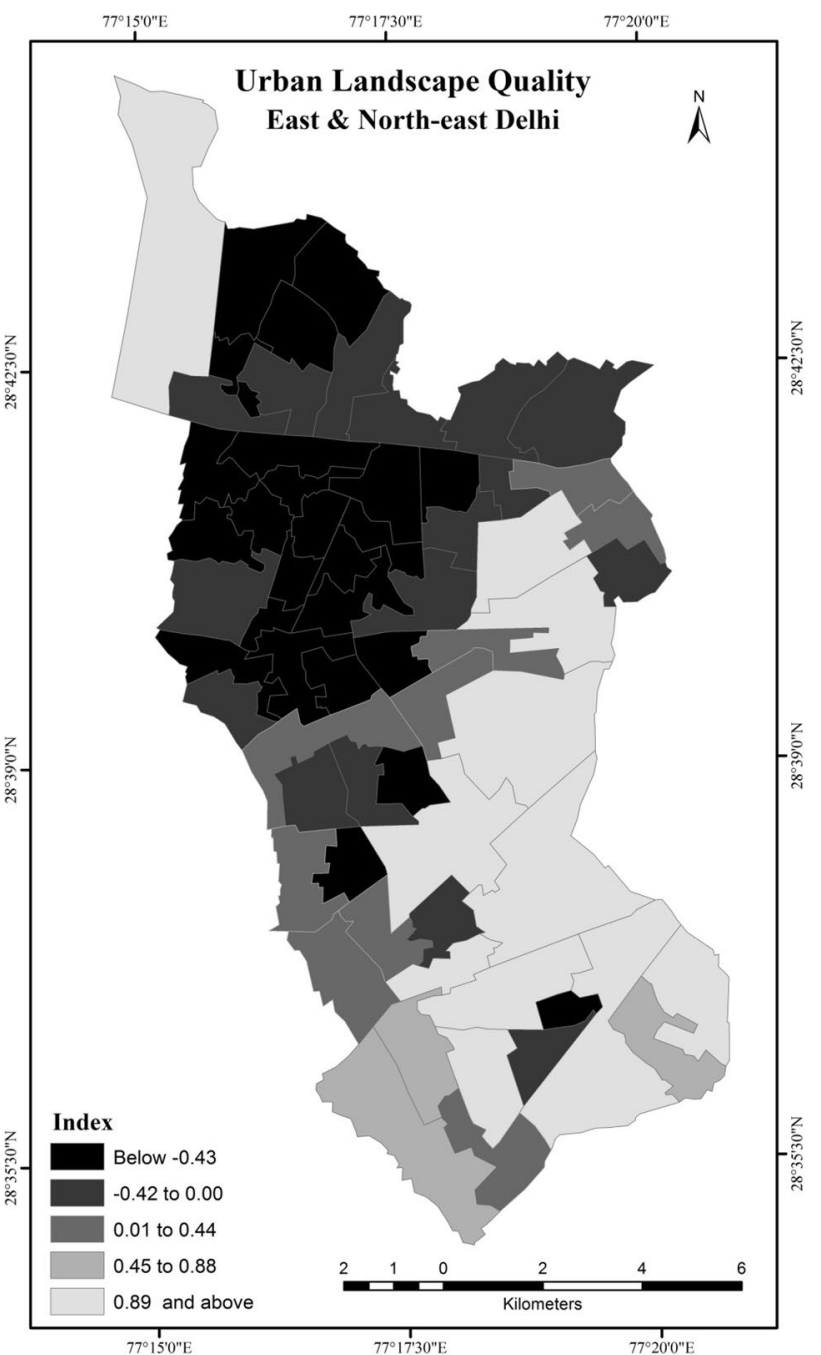

Fig. 5 Urban landscape quality in East and North-East Delhi

these wards. The wards of central and northern parts of the region like Nehru Vihar, Jhilmil, Shakarpur, etc., show low quality of landscape due to high population density and sparse distribution of the POS. Overall, the wards of south and eastern part have better landscape quality than rest part of the study area (Fig. 5).

The wards which have high density of population $\left(5,97,998\right.$ person $\left./ \mathrm{km}^{2}\right)$ reflect a lower landscape quality like Nehru Vihar which have a index score -1.23 . Seelampur, Sadatpur, Subhash Mohalla, Nehru Vihar, Nand Nagri, etc., also have high population density and low quality of landscape, while the wards which have low population density have best quality urban landscape such as Anand Vihar $(12,582)$ and Preet Vihar $(16,195)$, have the lowest population density and have highest index score Preet Vihar (3.25) and Anand Vihar (2.04) (Appendix-II). Besides, population density, open space and open green space are also important determining factors of landscape quality in 
the region. The wards like Sonia Vihar and Trilokpuri West, etc., have adequate open and green space and have good quality landscape, while wards like Sadatpur, Laxmi Nagar, Kanti Nagar, etc., have very low proportion of open and green spaces and have low quality of landscape.

\section{Discussion}

The urban landscape in India during twenty-first century is designed around the broad concepts like development of smart cities and industrial corridors [32]. The recent guideline of Ministry of Urban Development (MoUD) states that, if a plot of more than $10,000 \mathrm{~m}^{2}$ is to be developed, then a minimum $10 \%$ area is to be left under vacant either with or without green cover [47] to maintain landscape quality. But these rules are not followed in most of Indian cities including Delhi. It is noticeable that green patches or vegetation cover is found in clusters in the East and NorthEast Delhi. These green areas are mostly clustered in the periphery of the study area and disappear almost abruptly without a gradient either natural or human introduced to the landscape. The same spatial pattern is observable in almost all big cities of India and cities of other countries $[36,33]$. Therefore, it is the need of the hour to increase the public open spaces as well as the green spaces in order to attain a better landscape quality in the Indian cities which are experiencing fast population growth and urbanization.

The capital city of India New Delhi is the greenest metropolitan city of India with about $22 \%$ green cover, and the per capita green space is about $20 \mathrm{~m}^{2}$ compared to the other metropolitan cities like Mumbai and Chennai which has less than $10 \%$ green cover [9]. The per capita green space in Mumbai is $1.28 \mathrm{~m}^{2}$ [28], and Chennai has $0.46 \mathrm{~m}^{2}$ [63]. But in comparison with metropolitan cities, other big cities like Gandhinagar and Chandigarh have higher green spaces, i.e. $160 \mathrm{~m}^{2}$ and $55 \mathrm{~m}^{2}$ per capita green spaces, respectively [9, 23]. Jain et al. [30] analysed the landscape quality of Dehradun city; during past decades the city's status has changed from a tourist destination to an administrative and industrial centre which leads to densification of the city which leads to poor landscape quality. Sharma and Joshi [55] analysed the landscape dynamics of Delhi and found that the urban infilling has led to declining urban quality in the city. According to Census of India [6], the population of East Delhi has increased from 3.2 million in 2001 to 3.9 million in 2011, which has high impact on expansion of built-up area, and encroaching the open spaces, water bodies and green areas that resulted in lowering of landscape quality. The main reason of declining landscape quality in East Delhi is lacking in public open spaces with response to population distribution.
The public green area is not available in all parts of the cities, but it has important impact on the landscape quality of cities [20]. Public open spaces are at the centre of debate on urban sustainability and design because it is essential for the quality of life (QOL) of urban inhabitants [52]. In [National Forest Policy [49], it is envisaged that an urban area should have at least $33 \%$ of its geographical area under the green cover, but the proportion of POS is not sufficient in Indian cities $[22,46]$. The USA has developed a method of declaring a city as 'Tree City USA', while China has developed a system of 'National Garden City' based on certain criteria like per capita public open spaces, green space-total land ratio, green space canopy coverage, etc. [9] to maintain and analyse their urban landscape quality, but in India there is no such initiative.

The gap of knowledge in the relationship between POS and QOL originate from the lack of research in the area at various scales and changing urban form. Though studies on land use/cover and urban sprawl are pregnant with this information but never explicitly discuss. There are very few studies which analysed the relationships between one and more open spaces with QOL indicators [10, 62]. Garau and Pavan [19] analysed the landscape quality based on accessibility, management, protection, appearance, etc., of the QOL and physical, social and built environment of urban areas. The indicators of landscape quality were developed by linking the social and expert opinion [61] and using public opinion [60]. Luck and Wu [42] used a gradient analysis to study the landscape pattern of Phoenix city of USA by classifying the twenty-four urban land use classes into six open and residential classes in order. On the methodological count, studies have assessed landscape quality based on open and green spaces $[16,20$, 42]. The landscape quality is assessed based on weightage where weights were assigned on a scale of 1-5 for each type of open and green space Gavrilidisa et al. [20]. The index developed in present study is based on similar weighting as used by Gavrilidisa et al. [20] of public open spaces, and thus can be applied to assess landscape quality of other Indian cities as well which has similar physical, demographic as well as socio-economic structure.

\section{Conclusion}

The size and spatial arrangement of the POS in an urban area are indicators of the sustainability of the urban landscape. The study shows that the population density and location of a ward are the main factors of distribution of POS. The study further indicates that the wards with a high density of population have a low per capita share of POS. The location of wards also plays a crucial role in the distribution of POS, e.g. the wards close to Yamuna River 
and those in the northern part, where urban expansion is observed in the recent past, the per capita POS is high, while in the wards of central part of the region, the per capita POS is low. The study shows that 14 wards meet the WHO criteria of per capita green space availability, while only two wards match the UN criteria of per capita green space. The result shows that maximum wards fall under the very low to the medium category of urban landscape quality. Only 14 wards have landscape quality above a medium category. It is seen that population density is the main determinant of landscape quality because wards with higher population density have low landscape quality and vice versa.

As regard to spatial arrangement, green patches are highly clustered as confirmed by the $\mathrm{Rn}$ value of 0.56 returned by the nearest neighbour analysis. The services of these patches are inaccessible to the poor who do not possess motor vehicles. Further, their distance from built area is too far to have a cooling effect on the built-up area during summer. On the other hand, other POS are also not evenly distributed. These are randomly arranged over the space of the East and North-East Delhi as confirmed by Rn statistic of 1.46 . However, they are available in all wards in some measure or are nearby built-up area, therefore, accessible to a significant portion of the population. Hence, the researchers suggest that there is an urgent need to increase either open spaces or green open spaces or both so that landscape quality can be improved, which shall result in better quality of life of city's inhabitants.

Acknowledgements Authors highly appreciate the critical and constructive comments of both the learned reviewers. Their comments have undoubtedly helped in the improvement of the MS many folds. We also acknowledge the Google Earth for the data downloaded from www.google.com/intl/en_in/earth.

\section{Compliance with ethical standards}

Conflict of interest The authors declare that they have no conflict of interest.

\section{References}

1. Amin AM (2012) Sustainable urban landscape: an approach for assessing and appropriating indicators. Archnet-IJAR 6(2):98-114

2. Baral H, Holmgren $P$ (2015) A framework for measuring sustainability outcomes for landscape investments. In: Working paper 195. Center for International Forestry Research (CIFOR), Bogor, Indonesia

3. Bruni D (2016) Landscape quality and sustainability indicators. Agric Agric Sci Proc 8:698-705. https://doi.org/10.1016/j.aaspr 0.2016 .02 .047

4. Campos A, Oliveira RC (2016) Cluster analysis applied to the evaluation of urban landscape quality. In: WIT transactions on ecology and the environment, vol 204; ISSN 1743-3541. https:// doi.org/10.2495/sc160091

5. Cassatella C, Peano A (eds) (2011) Landscape indicators. Assessing and monitoring landscape quality. Springer, Dordrecht. ISBN 978-94-007-0366-7

6. Census of India (2011) http://censusindia.gov.in/2011-prov-resul ts/data_files/delhi/3_PDFC-Paper-1-tables_60_81.pdf. Accessed 08 Mar 2018

7. Cetinkaya G, Sözen N (2017) Towards sustainable landscape development indicators for north Cyprus. TÜBAV Bilim 10(1):75-85

8. Chang J, Qu Z, Xu R, Pan K, Xu B, Min Y, Ren Y, Yang G, Ge Y (2017) Assessing the ecosystem services provided by urban green spaces along urban centre-edge gradient; Scientific Reports. Nature 7:11226

9. Chaudhry P, Bagra K, Singh B (2011) Urban greenery status of some Indian cities: a short communication. Int J Environ Sci Dev 2(2):98

10. Chiesura A (2003) The role of urban parks for the sustainable city. Landsc Urban Plann 68(2004):129-138

11. Chou YU, Lee $\mathrm{CH}$, Chang CY (2016) Relationships between urban open spaces and human's health benefits from an ecological perspective: a study in an urban campus. Landsc Ecol Eng 12:255-267

12. Council of Europe (2000) Official text of the European landscape convention. http://www.coe.int/t/e/Cultural_Co-operation/ Environment/Landscape/. Accessed 4 Dec 2007

13. Council of Europe (2013) European landscape conventioncouncil of Europe. https://rm.coe.int/16802f1409. Accessed 25 Feb 2019

14. De Vries $S$, Van Dillen SME, Groenewegen PP, Spreeuwenberg P (2013) Streetscape greenery and health: stress, social cohesion and physical activity as mediators. Soc Sci Med 94:26-33

15. MCD Election (2017) http://www.elections.in/delhi/mcd-elect ions/mcd-ward-list-2017.html

16. Firmansyah, Soeriaatmadja AR, Wulanningsih R (2017) A set of sustainable urban landscape indicators and parameters to evaluate urban green open space in Bandung City. In: 3rd International symposium for sustainable landscape development (ISSLD 2017). IOP conference series: earth and environmental science, vol 179 (2018) p. 012016

17. Forest Research (2019) landscape quality: benefits of green infrastructure evidence note. https://www.forestresearch.gov. uk/tools-and-resources/urban-regeneration-and-greenspace -partnership/greenspace-in-practice/planning-integrated-lands capes/landscape-quality/

18. Forman RT, Godron M (1986) Landscape ecology. Wiley, NewYork

19. Garau C, Pavan VM (2018) Evaluating urban quality: indicators and assessment tools for smart sustainable cities. Sustainability 10:575. https://doi.org/10.3390/su10030575

20. Gavrilidisa AA, Ciocănea CM, Nita MR, Onose DA, Năstase II (2016) Urban Landscape Quality Index-planning tool for evaluating urban landscapes and improving the quality of life. Proc Environ Sci 32:155-167. https://doi.org/10.1016/j.proen v.2016.03.020

21. Google Earth. https://earth.google.com/web/@28.64696 $54,77.09326341,214.49322939 a, 163211.06262$ 852d,35y,0h,0t,0r/data=CkkaRxl_CiQweDM5MGNmZDViMzQ3 ZWI2MmQ6MHgzNzIwNWI3MTUzODk2NDAZq3JGOT20PEAhR UoOM49GU0AqBURlbGhpGAlgASgC. Last accessed 17 Oct 2018

22. Govindarajulu D (2014) Urban green space planning for climate adaptation in Indian cities. Urban Clim 10:35-41. https://doi. org/10.1016/j.uclim.2014.09.006

23. Gupta K, Kumar P, Pathan SK, Sharma KP (2012) Urban Neighborhood Green Index-a measure of green spaces in urban areas. Landsc Urban Plan 105(3):325-335 
24. Hall P, Ward C (1998) Sociable cities: the legacy of Ebenezer Howard. Wiley, Chichester

25. Haq SMA (2011) Urban green spaces and an integrative approach to sustainable environment. J Environ Prot 2:601608 (scientific research)

26. Hartig T, Mitchell R, De-Vries S, Frumkin H (2014) Nature and health. Annu Rev Public Health 35:207-228. https://doi. org/10.1146/annurev-publhealth-032013-182443

27. Hillsdon M, Panter J, Foster C, Jones A (2006) The relationship between access and quality of urban green space with population physical activity. Public Health 120:1127-1132

28. HT (2018) Mumbai to get more open space per person. https ://www.hindustantimes.com/mumbai-news/mumbai-toget-more-open-space-per-person/story-5BtDAXun2YvuEJm 3pvw6NM.html

29. Iyer NK, Kulkarni S, Raghavaswamy V (2007) Economy, population and urban sprawl a comparative study of urban agglomerations of Bangalore and Hyderabad, India using remote sensing and GIS techniques. In: Workshop on urban population, development and environment dynamics in developing countries jointly organized by CICRED, PERN and CIESIN with support from the APHRC, Nairobi. http://www.cicred.org/Eng/ Seminars/Details/Seminars/PDE2007/Papers/IYER_Neelakanta n_paperNairobi2007-project.pdf

30. Jain S, Laphawan S, Singh PK (2013) Tracing the Changes in the pattern of urban landscape of Dehradun over last two decades using RS and GIS. Int J Adv Remote Sens GIS 2(1):351-362

31. Khalil R (2014) Quantitative evaluation of distribution and accessibility of urban green spaces (Case study: City of Jeddah). Int J Geom Geosci 4(3):2014

32. Khosla R (2017) India's urban landscape. Econ Polit Wkly 52(1):92-101

33. Kiichiro K (2008) Analysis of vegetation distribution in urban areas: Spatial analysis approach on a regional scale. In: The international archives of the photogrammetry, remote sensing and spatial information sciences, vol 37. Part B8. Beijing

34. Knorr $L$ (2011) the birth of the theory of urban green systems in Britain and Hungary, Correspondence between Thomas $\mathrm{H}$. Mawson and Béla Rerrich concerning Urban Design Principles. In: First international conference on "Horticulture and Landscape Architecture in Transylvania". Agriculture and Environment Supplement, pp 41-53

35. Kuchelmeister G (1998) Urban forestry: present situation and prospects in the Asia and Pacific region, FAO Asia-Pacific Forestry Sector Outlook Stud, Rome. Food and Agriculture Organization of the United Nations, Forestry Policy and Planning Division

36. Kumagai K (2006) Analysis of the spatial continuity of vegetation-covered areas on a regional scale. In: Proceedings of the 27th Asian conference on remote sensing, Chinggis Khaan Hotel, Mongolia, 9-13 Oct 2006

37. Kumar R (2017) Overview: social spaces in urban areas. Int Res J Eng Technol 4(4):1032-1039

38. Kurban A (2017) Bioclimatic urban green indicators for the sustainability of cities in arid environments. Int J Appl Sci Technol 7(2):26-37

39. Lestan KA, Eržen I, Golobič M (2014) The role of open space in urban neighbourhoods for health-related lifestyle. Int J Environ Res Public Health 11:6547-6570

40. Li L, Pussella PGRNI (2017) Is Comombo City, Sri Lanka secured for urban green space standards. Appl Ecol Environ Res 15(3):1789-1799. https://doi.org/10.15666/aeer/1503_17891 799

41. Li F, Zhang F, Li X, Wang P, Liang J, Mei Y, Cheng W, Qian Y (2017) Spatiotemporal Patterns of the use of urban green spaces and external factors contributing to their use in central Beijing. Int J Environ Res Public Health 14:237

42. Luck M, Wu J (2002) A gradient analysis of urban landscape pattern: a case study from the Phoenix metropolitan region of USA. Landsc Ecol 17:327-329

43. MacKendrick NA, Parkins JR (2004) Framework for assessing community sustainability: a synthesis of current research in British Columbia. Information Report Nor-X-392, Northern Forestry Centre, Canada

44. Matsushitaa B, Xu M, Fukushimaa T (2006) Characterizing the changes in landscape structure in the Lake Kasumigaura Basin, Japan using a high-quality GIS dataset. Landsc Urban Plan 9:241-250

45. Mitchell R, Popham F (2008) Effect of exposure to natural environment on health inequalities: an observational population study. Lancet 2008(372):1655-1660

46. Mitra P (2013) Open space shrinking, city gasps for breath. In: Times of India, May 2013 https://timesofindia.indiatimes.com/ city/kolkata/Open-space-shrinking-city-gasps-for-breath/artic leshow/20188789.cms

47. MoUD (2016) Model building bye-laws-2016. Town and country planning organisation, Ministry of Urban Development. http:// www.indiaenvironmentportal.org.in/files/file/MODEL\%20BUI LDING\%20BYE\%20LAWS-2016.pdf

48. Municipal Corporation of Delhi (MCD) (2017) Election-Ward Map. http://mcdonline.gov.in/tri/edmc_mcdportal/wardlist. php. Accessed 10 Mar 2017

49. National Forest Policy (1988) Ministry of environment and forest, Government of India

50. Nega T, Fu WH, Vrtis G (2010) Open space index: a GIS-based tool for assessing human penetration of a landscape. Local Environ 15(8):743-759

51. Rahman A, Kumar S, Fazal S, Siddiqui MA (2012) Assessment of land use/land covers change in the north-west district of Delhi using remote sensing and GIS techniques. J Indian Soc Remote Sens 40(4):689-697

52. Rakhshandehroo M (2014) Establishing new urban green spaces classification for Malaysian Cities. In: Conference: IFLA 2014 Asia Pacific congress, Kuching, Malaysia. https://doi.org/10.13140/ rg.2.1.3912.6880

53. Rogers R (1997) Cities for a small planet. Faber and Faber, London

54. Salem D (2016) Visions for Urban landscape sustainability, past, present and future. Eur J Sustain Dev 5(3):419-432

55. Sharma R, Joshi PK (2013) Monitoring urban landscape dynamics over Delhi (India) using remote sensing (1998-2011) Inputs. J Indian Soc Remote Sens 41(3):641-650

56. Sherbinin AD, Carr D, Cassels S, Jian L (2007) Population and environment. Annu Rev Environ Resour 2007(32):345-373. https ://doi.org/10.1146/annurev.energy

57. Shriganesh B, Markandey K (2016) Rethinking urban space in cities-a study of parks in Hyderabad, India. IOP Conf Ser Earth Environ Sci 37:1-8. https://doi.org/10.1088/17551315/37/1/012052

58. Singh VS, Pandey DN, Chaudhary P (2010) Urban forests and open green spaces: Lessons for Jaipur, Rajasthan, India. Rajasthan State Pollution Control Board 4-Jhalana Institutional Area Jaipur 302017, Rajasthan, India. http://www.indiaenvir onmentportal.org.in/files/RSPCB-OP-1-2010.pdf

59. Sowińska-Świerkosz B (2017) The application of surrogate measures of ecological quality assessment: the introduction of the Indicator of Ecological Landscape Quality (IELQ). Ecol Indic 73:224-234

60. Sowińska-Świerkosz B, Chmielewski TJ (2014) Comparative assessment of public opinion on the landscape quality of two biosphere reserves in Europe. Environ Manag 54:531-556 
61. Sowińska-Świerkosz B, Chmielewski TJ (2016) A new approach of the identification of Landscape Quality Objectives (LQOs) as a set of indicators. J Environ Manag 184:596-608

62. Sugiyama T, Francis J, Middleton NJ, Owen N, Giles-Corti B (2010) Associations between recreational walking and attractiveness, size, and proximity of neighborhood open spaces. Am J Public Health 100(9):1752-1757

63. The Hindu (2012) Where is our patch of green, Mr. Mayor. https ://www.thehindu.com/news/cities/chennai/where-is-our-patch -of-green-mr-mayor/article3223739.ece

64. Tveit M, Ode Sang A (2014) Landscape assessment in metropolitan areas-developing a visual indicator-based approach. SPOOL. https://doi.org/10.7480/spool.2013.1.641
65. Villanueva K, Badland H, Hooper P, Kooshari MJ, Mavoa S, Davern M, Robert R, Goldfeld S, Corto BG (2015) Developing indicators of public open space to promote health and well being in communities. Appl Geogr 57:112-119

66. Wu J, David J (2002) A spatially explicit hierarchical approach to modeling complex ecological systems: theory and applications. Ecol Model 153:7-26

Publisher's Note Springer Nature remains neutral with regard to jurisdictional claims in published maps and institutional affiliations. 